$$
\begin{array}{r}
D R \cdot 1242-4 \\
I-22459
\end{array}
$$

\title{
Calculating the Vulnerability of Synthetic Polymers to Autoignition During Nuclear Flash Final Report
}

R. Hickman

T. Reitter

March 1985

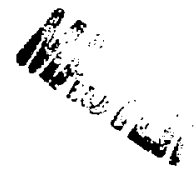




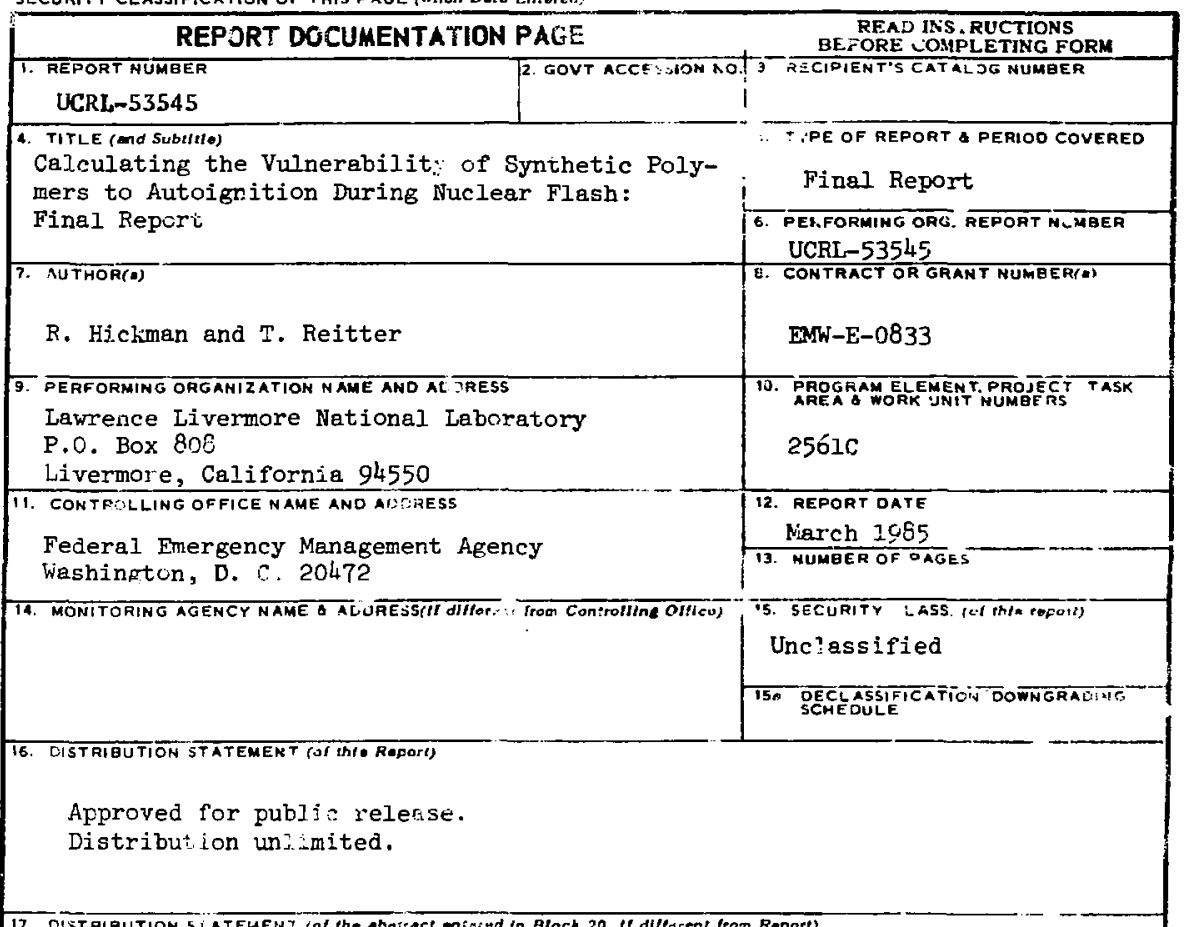

17. OIST

18. SUPPLEMENTARY NOTES

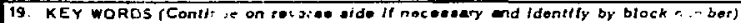

Nuclear flash

Encore

flashover

fire igrition

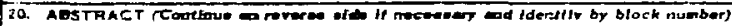

In an experiment that was part of a 1953 nuclear best (Encore), a furnished room exposed to nuclear heat was completely consumed when th fire unexpectedly progressed to lashover. The result $\mathrm{cl}$, his wique experitient has been call $\approx \mathrm{d}$ an "anomaly," but a flashover under these conditions may actualiy be typical (and consequently worth further exploratic.:). The ceiculations detailud in this report repreaent a first approach to this question.

Bocause synthetic polymers in the form of urnishings ar more common in 
20. (cuntinued)

modern twellings t: tire cellylose baced rater:als used in the 1953 experimert, have enphasizer the polymer; in our calculations. our investigations have virtually ri.led out photochemical processes as an explar: 'ston of pa.tt -. future flashovers induced ' $y$ nuclear detonation. Our calculations of rafid raoilant htiting if a few common synthetic materials show they wruld quickly ignita when exposed to a $2 \vdots \cdots a I \mathrm{~cm}^{2} \mathrm{f}$ ence from a l-Mt weapon deton ted in the air. This res'. $E$, toget. or with the fact tinat synthetic polya. :s have higher heat is ralues and release ieat at a higher rate during combustion, suggests that modern dwellings are vulnerable to nuclear-flashinduced flashover. A definitive answer to the questicn, however, nust awail carefully planned, full-scale experiments. 
UCRL-535:5

Distribuzion Category UC -41

\section{DISCLAIMER}

This repanc was prezared as an account of work sponsored by an agency of the United States Government. Neitter the United Sisits Governmem an any agency thered, nor eny of theit employes, makes any warranty, express or itaplied, or aevumes any legal liability or raspossibility for the aceuracy, comptetenes, or usefulness of any information, apparatus, produch or process disclosed, of reprezents that its was: wouls not infringe privately owned rights. Reference herein to any specific commencial porpduct, process, or service by lode name, trademart mianufacturw, or otherwise does not : mendation, of favisiug by the Unitcs States fovernment or any aseacy thereof. The vitus and opinions of authors expressed iserein do not necesteribly state ot reflect thowe of the United States Government or any sgency thereof.

\section{Calculating the Vulnerability of Synthetic Polymers to Autoignition During Nuclear Flash Final Report}

JCRL -53545

$D E 85 \quad 016549$

R. Hickm:an

T. Reitter

Manuscript date: March 1985 


\begin{abstract}
In an experiment that was part of a 1953 nuclear test (Encore), a furnished room exposed to nuclear heat was completely consumed when the fire unexpectedly progressed to flashover. The result of this unique experiment has been called an "anomaly," but a flashover under these conditions may actually be typical (and consequently worth further exploration). The calculations detailed in this report represent a first approach to this question.

Because synthetic polymers in the form of furnishings are more common in modern dwellings than the cellulose-based materials used in the 1953 experiment, we have emphasized the polymers in our calculations. Our investigations have virtually ruled out photochemical processes as an explanation for past or future flashovers induced by nuclear detonation. Our calculations of rapid radiant heating of a few common synthetic materials showed they would quickly ignite when exposed to a $25-\mathrm{cal} / \mathrm{cm}^{2}$ fluence from a 1-Mt weapon detonated in the air. This result, together with the fact that synthetic polymers have higher heating values and release heat at a higher rate during combustion, suggests that modern dwellings are vulnerable to nuclear-flash-induced flashover. A definitive answer to the question, however, must await carefully planned, full-scale experiments.
\end{abstract}




\section{Contents}

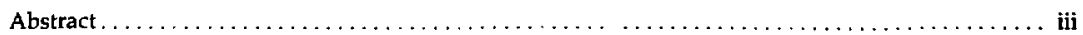

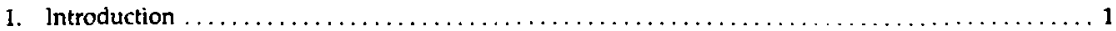

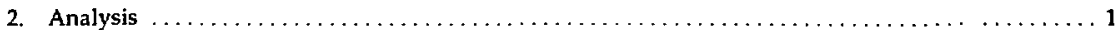

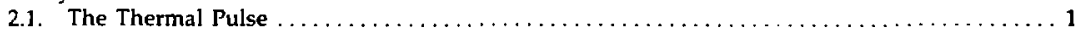

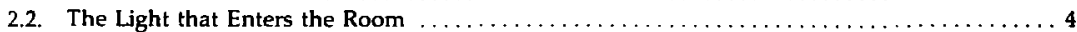

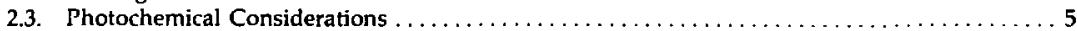

2.4. Beyond Photochemistry $\ldots \ldots \ldots \ldots \ldots \ldots \ldots \ldots \ldots \ldots \ldots \ldots \ldots \ldots \ldots \ldots \ldots, \ldots \ldots$

2.5. Surface Absorption: Allowance for Thermal Transport $\ldots \ldots \ldots \ldots \ldots \ldots \ldots \ldots \ldots \ldots \ldots$.

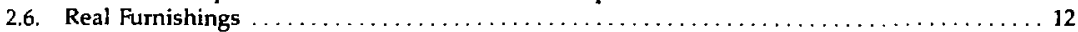

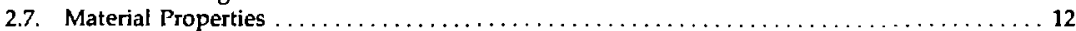

2.8. Numerical Integration of the Heat-Conduction Equation $\ldots \ldots \ldots \ldots \ldots \ldots \ldots \ldots \ldots \ldots$

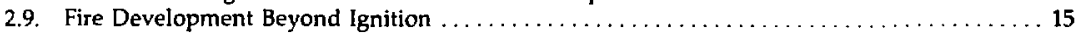

2.10. Interaction of Ignited Fires with the Blast Wave $\ldots \ldots \ldots \ldots \ldots \ldots \ldots \ldots \ldots \ldots \ldots \ldots$

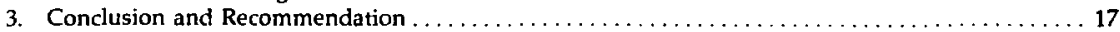

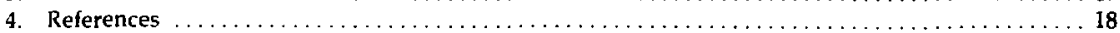




\section{Calculating the Vulnerability of Synthetic Polymers to Autoignition During Nuclear Flash Final Report}

\section{Introduction}

In 1953, ar interesting experiment, which was designated as the Encore Event,' was conducted as part of the atmospheric nuclear test series called Upshot-Knothole. In this experiment, two identical wooden structures were placed at a distance from the nuclear device (whose yield was measured at $27 \mathrm{kt}$ ) where their front surfaces would receive about $25 \mathrm{cal} / \mathrm{cm}^{2}$ of light energy. (As used in this report, the word "light" means electromagnetic energy in the ultraviolet, visible, infrared, and far infrared spectral ranges regardless of its intensity.) Each structure was closed except for a large, unglazed window facing the detonation. One structure was furnished with typical American consumer products-generally cellulosic in nature, such as paper, rayon and cotton clothing, cotton-upholstered furniture (including a sofa), rugs, and curtains. The other structure contained furnishings made mainly from wool-based fabrics (although some wood and magazines were retained); the curtains were vinyl, as was a chair cover; a second overstuffed chair was used in lieu of the sofa in the first structure.

When the device was detonated, both structures were scorched, and some fire was observed within each structure. More fire apparently was ignited in the structure with cellulose-based furnishings, and it must have grown in intensity at a higher rate. When the shock wave arrived, most of the wool furnishings were wholly or substantially extinguished, but the better-established fire in the first structure continued to grow in intensity. Within about 30 seconds, that room was fully engulfed in flame (flashover), and the structure burned to the ground.
It was expected that the cellulosic materials would catch fire; but swift progression of the fire to flashover conditions was not expected. Considering the implications this experiment had for expedient fire fighting by the civilian population, it is remarkable that these results were largely ignored in the preparation of civil defense manuals for nearly 30 years. The episode came to be known as the "Encore anomaly," and only a few researchers saw the possibility that the phenomenon might be a normal occurrence.

Some additional tests were conducted in $\mathbf{1 9 5 5}$ on the response of fabrics and synthetic polymers to pulse-heating from a nuclear explosion. ${ }^{2}$ The results, however, were measured and reported in such a qualitative way that they are of no use in explaining the Encore observation.

Rather recently the Encore anomaly was recalled, and the following question was posed:

If the Encore response is typical, what do we know or what can be calculated about the behavior of rooms exposed to a thermal output from a modern strategic weapon if these rooms are furnished with modern synthetics rather than cellulosics?

In this report we set forth what we expect on the basis of rudimentary calculations. Our investigation is constrained by a dearth of information; moreover, we are limited to theoretical analysis without recourse to experiment.

\section{Analysis}

\subsection{The Thermal Pulse}

Before giving details of our analysis, we must address the issue of nuclear yield because thermal response is flux-dependent. ${ }^{3}$ Table 1 shows that more fluence is required to cause ignition from high-yield weapons than from low-yield weapons. Because high-yield weapons deliver energy 
Table 1. Approximate radiant exposures for ignition of various materials for low air burst (see Ref 3).

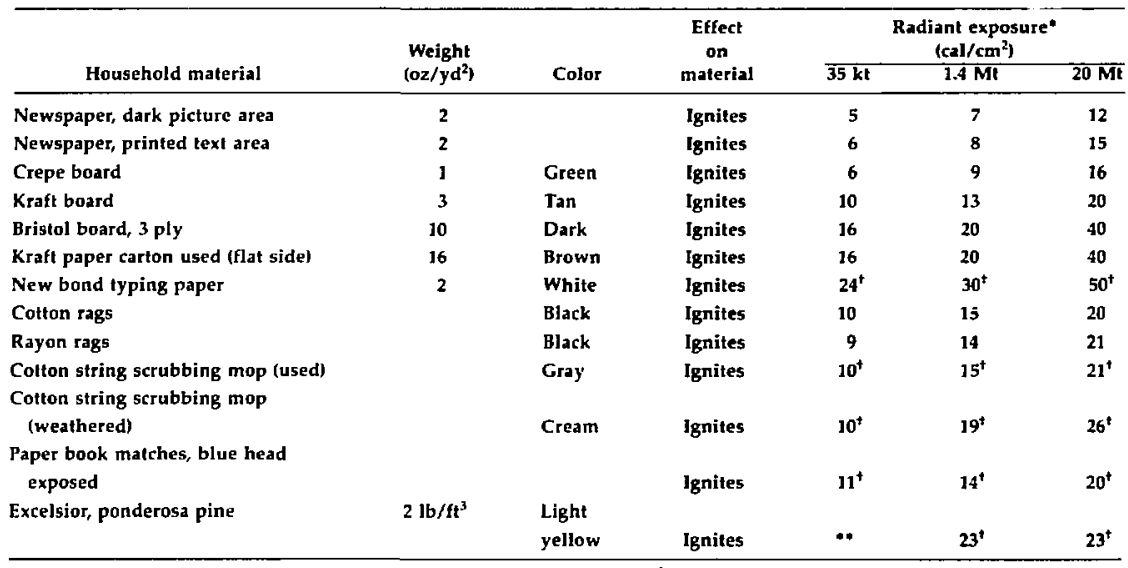

" Radiant exposures for the indicated responses (except where marked ") are estimated to be valid to $\pm 25 \%$ under standard laboratory conditions. Under typical field conditions, the values are estimated to be valid within $\pm 50 \%$ with a grealer likelihood of higher rather than lower values. For materials marked ${ }^{\dagger}$, ignition levels are estimated to be valid vithin $\pm 50 \%$ under laboratory conditions and within $\pm 100 \%$ under field conditions.

* Data not available, or appropriate scaling not known.

over a much longer time, energy-transport processes can develop that in turn lower the rate of temperature increase and also reduce the maximum surface temperature reached by the cloth for a given fluence. We chose a yield of $1 \mathrm{Mt}$ because a recent study suggested that the Soviet Union has stockpiled thousands of strategic warheads with yields of $800 \mathrm{kt}$ and $1.5 \mathrm{Mt}^{4}$ Because explosion effects vary approximately as the cube root of the yield, just over a mile's distance reduces the difference in weapons effects; hence, $1 \mathrm{Mt}$ is an adequate approximation for either Soviet warhead.

The thermal pulse shape is not a Dirac delta function, but rather a pair of peaks separated in time by about $0.8 \mathrm{~s}$. The first peak is very sharp and contains about $1 \%$ of the total energy. The second is rather broad and lasts more than $10 \mathrm{~s}$ at this yield, but most of the energy has been emitted in $10 \mathrm{~s}$. This time history is shown in Fig. 1 (Ref. 5). Initially the electromagnetic radiation is of very short wavelength, but by the time it is of interest for this study, interaction with the air has moderated it down to a spectrum very similar to that of the sun at sea level, with most of the energy in the visible part of the spectrum. The emitted spectrum from the fireball is very similar to a blackbody radiator at about $6200 \mathrm{~K}$, except for minor depletion in the ultraviolet that results from absorption in the air. Because of the high temperature of the fireball, the radiant energy is much more energetic per photon than that given off by radiant preheaters typically used in fammability tests. An appreciation of these differences is gained from simply recalling that the radiant power per unit area increases as the fourth power of the absolute temperature, and that the highest emission flux shifts to shorter wavelength in proportion to the reciprocal of absolute temperature. (At late times the spectrum is shifted toward the red, but that fine detail is ignored for this analysis.)

The height of burst is important for at least two reasons: At very high altitudes a fireball (for purposes of this study) will not even form. The altitude also influences the time of shock arrival, as well as the shock pressure-jump and the duration of the positive pressure phase. These factors, in turn, determine the amount of blast damage to structures. For the purpose of this exercise, we stipulate that detonation occurs at $7500 \mathrm{ft}$. At this altitude, the blast-damage area at the 10-psi maximum overpressure behind the shock is maximized, as Fig. 2 shows. ${ }^{6}$ Heights and distances have been scaled by the cube root of the ratio of yields, i.e., $(1 \mathrm{Mt} / 1 \mathrm{kt})^{1 / 3}=10$. Because such overpressure will wreck most civilian structures, 7500-ft detonation is a reasonable strategy for an 


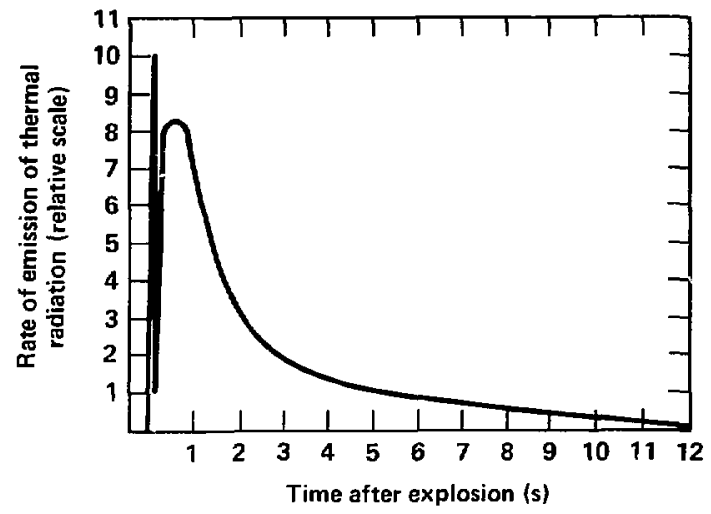

Fig. 1. Emission of thermal radiation in a 1-Mt air burst.

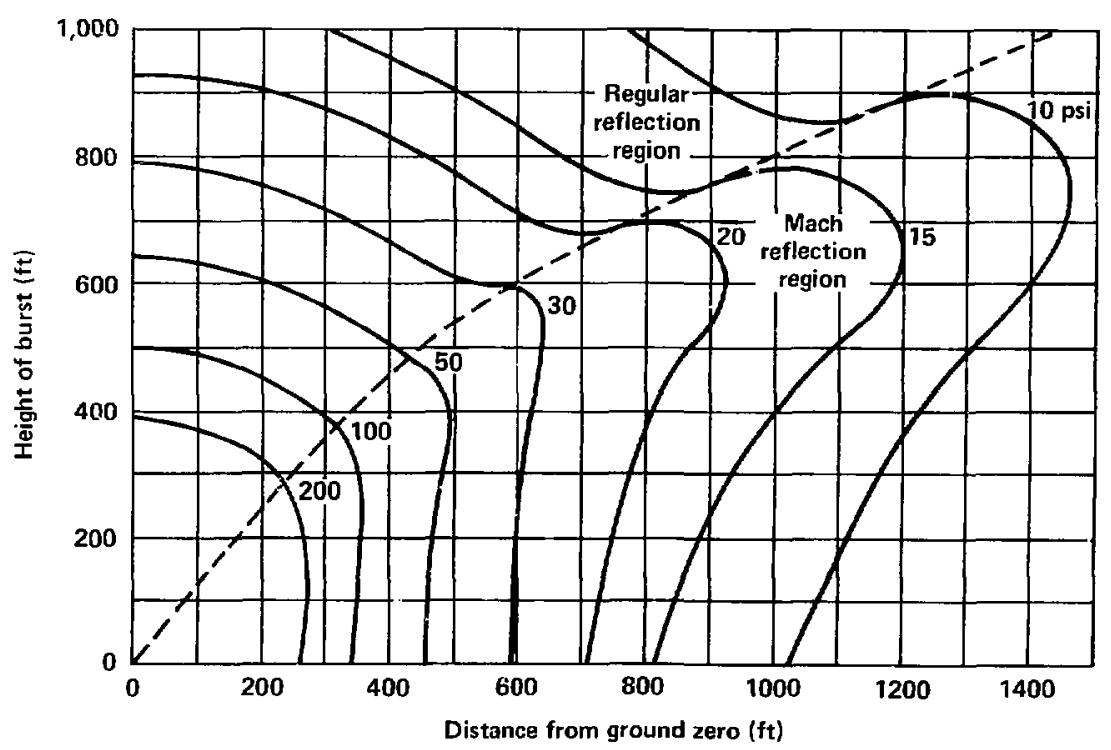

Fig. 2. Peak overpressures on the ground for a 1-kt burst (intermediate-pressure range). 
attack on unhardened largets. This altitude also obviates air-density corrections and simplifies the calculations that follow.

Another selected parameter is that the stmosphere is fairly clear, with $12-\mathrm{mi}$ visibility. Selection of other degrees of atmospheric clarity (5- to 100-mi visibility) would give only slightly different thermal fluences at distances of interest. When the visibility is poorer, the fluence is nearly the same, but a larger fraction has been diffusely scattered, and the spectrum is shifted stightly to longer wavelengths.) This assumption about the atmosphere is quite arbitrary, but it allows us to continue.

Another factor to consider is the distance(s) from ground zero: close in, ail strurtures are destroyed and all exposed combustibles are burned. Far away, nothing of consequence happens. To calculationaily consider the Encore plenomenon, we must select a location for our structures far enough away for most or many of them to survive, even though they may sustain substantial damage. In order to determine this distance, we have chosen a mavimum overpressure of $4.0 \mathrm{psi}$, a level that will hedvily damage some residential structures but should leave many standing, along with many of the more rugged oritice buildings. In a free-field situation, this pressure would be realized at a distance of $\mathbf{4 . 6}$ miles, measured horizontally from the point beneath the explosion. Given the other stipulations, it is then simple to determine that the fluence of light energy at this distance will be $35 \mathrm{cal} / \mathrm{cm}^{2}$. It should be noted that thermal response of rom-furnishing materials is flux dependent."

\subsection{The Light that Enters the Room}

Choosing a clear day greatly simplifies the problem of calculating the amount of light reflected by a window. We stipulate that the opening to the room is a window fitted with standard soda-lime window glass. We ignore reflection from ather buildings or the possibility of shadowing from them or from trees or shrubs.

Next, we stipulate normal incidence of light against the window , ane. We also stipulate a single pane of glass, rather than storm windows or thermopane windows, which would introduce the cornplication of many riultiple reflections. Finally, we allow reflection from not only the outer air/glass interíace, but also from the inner glass/air interface, thus taking into account multiple internal reflections within the single pane of glass.
Under these assumptions, then, the fraction of incident light transmitted is given by $y^{-}$

$T=\frac{(1-R)^{2} \exp (-\beta L)}{1-R^{2} \exp (-2 \beta L)}$,

where

$\mathrm{T}=$ fraction of incident light transmitted,

$R=(n-1)^{2} /(n+1)^{2}$,

$\mathbf{n}=$ real part of the glass refiactive index,

$\beta=$ the absorption coefficient of the glass, which is directly related to the imaginary part of $n$,

$L=$ thickness of the glass.

To use this expression exactly it must be kept in mind that $\beta$ is never zero, although it can be very small, and that $n$ and $\beta$ are both wavelengthdependent. For this treatment, however, we violate our own admonition, set $\beta=0$, and make the light specular and monochromatir. Then Eq. (1) reduces to

$T=\frac{2 n}{n^{2}+1}$

if there are no absorption losses.

We also stipulate that the refractive index of air to be 1, when actually that is true only for vacuum. Then, taking the refractive index for typical window glass at the sodium $\mathrm{d}$ line (which is the usual optical standard, with wavelength $589.3 \mathrm{~nm}$ ), the value of $\mathrm{n}$ is about 1.58 and $\mathrm{T}=$ 90.4. Refractive index values of other common glasses range from 1.54 to 1.83 (Ref. 8).

We note that we have ignored the absorption in the glass that does occur at both the ultraviolet and infrared ends of the spectium emitted from the fireball. Rather tban integrating Eq. (1) for all wavelengths and including the absorption coefficients, we close this part of the analysis by assertion: The UV transmission cut-off for window glass is about $370 \mathrm{~nm}$ and the IR cut-off is $2700 \mathrm{~nm}$. About $9.4 \%$ of the energy in the incident spectrum is absorbed, so $81 \%$ is finally available to impinge on the room furnishings at normal incidence.

We also note that few (if any) windows will directly face the center of the fireball (normal incidence): Most will lie at an angle, giving added reflection on the outer surface. This can be calculated with Fresnel's formula

$R=\frac{1}{2} \frac{\sin ^{2}(i-r)}{\sin ^{2}(i+r)}+\frac{\tan ^{2}(i-r)}{\tan ^{2}(i+r)}$ 
where $R$ is the reflected fraction from the front surface, $i=$ the incident angle relative to the normal, and $r=$ the refracted ar. $b^{\text {le }}$ relative to the normal.

The incident (i) and refracted ( $r$ ) angles are calculateu' from Snell's law: $n_{i} \sin (i)=n_{s} \sin (r)$, and $n_{1}$, the refractive index of air, is taken as 1.00 . The incident angle is usually given, thus allowing calculation of the refracted angle. For example, if $j-45^{\circ}$, then (for $n_{r}=1.58$ ) $r=26.6^{\circ}$. Using Eq. (3), the reflected fraction for the appropriate wavelength is 0.061 , compared with $R=0.0505$ for normal incidence. Clearly, angle of incidence is a second-order effect, and it is not considered further. To sunimarize, about $80 \%$ of the light from the fireball will be considered to pass through a single pane of glass and shine on things within a room.

\subsection{Photochemical Considerations}

Once the light from the fireball has passed 'gh the window' glass, the next question is, whiu happens? As with the glass, there are only three possibilities when the light falls on the room interior or its furnishings: (1) reflection, (2) transmission, and (3) absorption. From common experience, we know that certain colors in the visible spectrum are preferentially reflected from many furnishings. Notable exceptions are surfaces that appear white ("everything" reflected) and black ("nothing" reflected). Every colored surface reflects the complementary color(s) of those absorbied. The governing macroscopic or continuum law's of optics are the same as stated earlier. Now, however, the imaginary part of the refractive index giving rise to strong absorption bands is very large.

Similarly, in a radiantly preheated standardized ignition, test, absorption orcurs in only certain spectral regions. Because these regions lie in the infrared, this selectivity is not visually appurent. To illustrate the complexity of this absorption, we show in Fig. 3 (Ref. 10) the typical functional groups' absorption from some classes of organic molecules that can be incorporated into synthetic polymers. These absorption bands are at wavelengths characteristic of interatomic vibrations (heating) and do not lead directly to chemical reaction. When we consider interaction of visible light, it is important to remember that the photons carry energy such that they interact with the valence electrons in the chromrphoric groups in the molecules. This is how dyes ar: 1 colorants, in general, work. Because of the energies involved, light between 300 and $400 \mathrm{~nm}$ in wavelength has sufficient energy not only to put these electrons into excited states, but also to actually break chemical bonds (see Table 2). Both carbon-carbon and oxygen-oxygen single bonds can be broken with about $80 \mathrm{kcal} / \mathrm{mole}$. Thus, we must consider the possibility of photolysis in addition to the more usual concern for pyrolysis as a step leading toward ignition and fire development. Furthermore, electrons raised to excited states with energies below $80 \mathrm{kcal} / \mathrm{mole}$ also can undergo photochemical reaction, so bond breaking as an initial step is not required.

While Table 2 show's the energies associated with the wavelength, Table 3 shows the energy associated with the first excited clectronic state for the singlet and triplet configurations of some double bonds in organic molecules. (Singlet and triplei simply refer to degeneracy resulting from different electron-spin orientations.) As would be expected according to Hunt's rule, the triplets are less energetic than the singlets, hecause there : more electron-electron repulsion in the latter case when the spins are pairod.

The polymeis used in modern home ar $d$ of fice furnishings are so diverse that we decided to consider the probability of photolysis rather than to further extend the investigation on the possibility. Just because a photochemic.] reaction is possible on the basis of energetics doesn't necessarily mean it will occur. Required proximity of reactants may be a hinderance, especially in solids. Recombination of products may occur so the reaction isn't observed. Finally, other nonphotochemical processes may compete for the absorbed energy of the photon.

To study the probabilities, we start with the assumption that light, in fact, will be absor bed. Then we consider the various processes that can occur, with special emphasi's on the experimen. tally obser'ed relative rates of the processes. Often two or more processes provide competitive alternatives, so the faster process will dominate. As an example we picked formaldehyde, a very simple molecule used to make some plastics. Formaldehyde is used to make the plastic, but once made, it is part of a polymer and its chemical behavior changes. Thus, much of the chemical information on the behavior of the formaldehyde molecule will not apply exactly to polymers based on the molecule. Similar information on polymers isn't available," however, so for illustrative purposes, formaldehyde serves as an ideal simple model. A real polymer or even a large molecule with several different chromophoric groups exhibits very complicated behavior, but the generic 


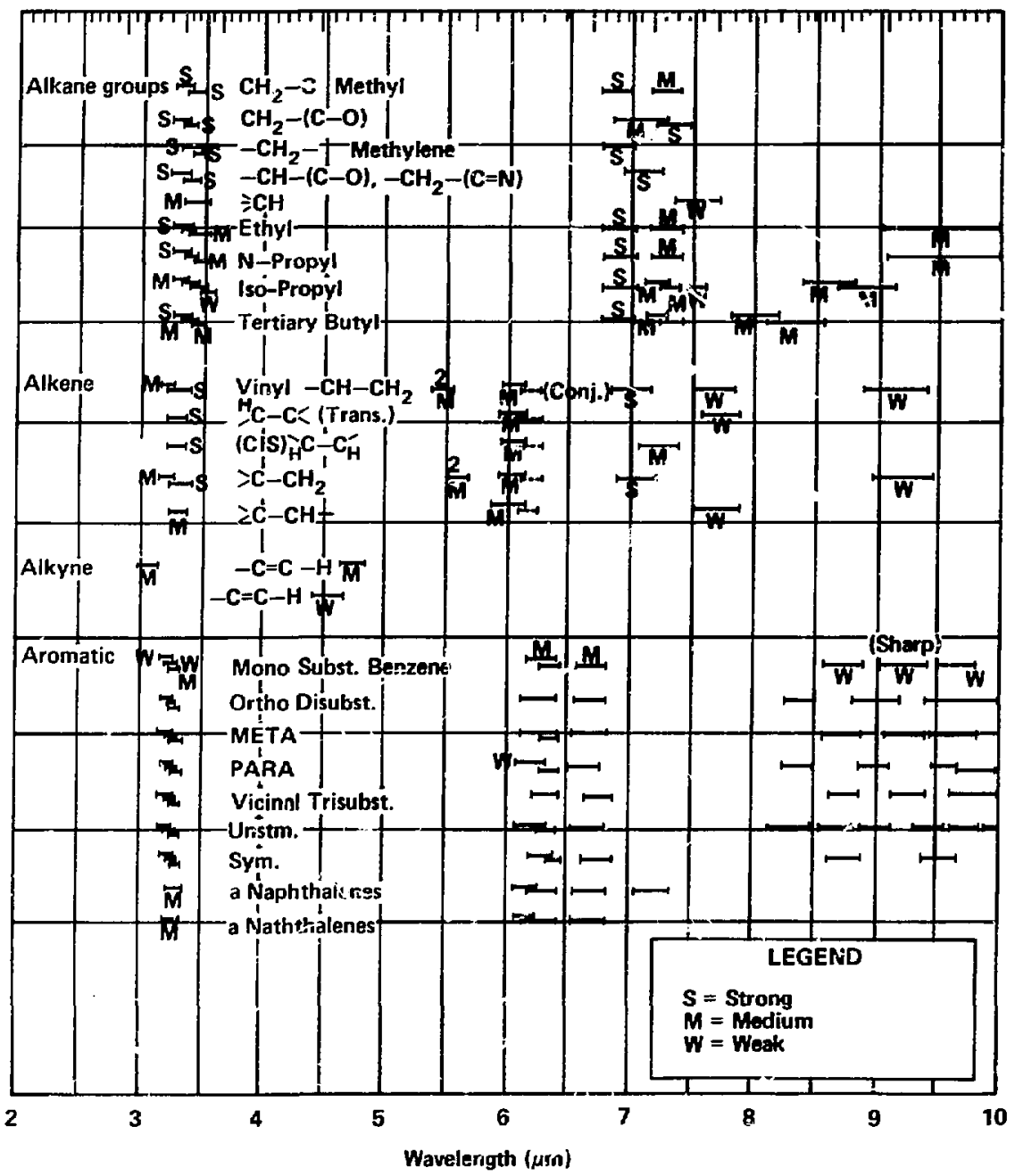

Fig. 3. Infrared correlation chart No. 1. (P1 epared from information supplied by Beckman Instruments.) 
Table 2. Photochemical region of the alectromagnetic spectrum (200 to $700 \mathrm{~nm}$ ) and respective photori enerģies.

\begin{tabular}{cc}
\hline Wavelength (nm) & Energy (kcal/mole) \\
\hline 200 & 143 \\
300 & 95 \\
400 & 71 \\
500 & 57 \\
600 & 48 \\
700 & 41 \\
\hline
\end{tabular}

Table 3. Energies of electronic excited states.

\begin{tabular}{lcc}
\hline \multicolumn{1}{c}{ Molecule } & $\mathrm{S}_{1}$ (kcal/mole) & $\mathrm{T}_{1}$ (kcal/mole) \\
\hline Benzene & 115 & 85 \\
Napthalene & 90 & 61 \\
1-Chloronphalene & 89 & 59 \\
Anthracene & 76 & 42 \\
Benzophenone & 75 & 69 \\
Acetone & 84 & 78 \\
\hline
\end{tabular}

kinds of transitions they can show are adequately explained by using the formaldehyde molecule. The fact that formaldehyde can actually be incorporated into a polymer is incidental.

Figure 4 is an energy diagram that shows how absorption, vibrational relaxation, and intersystem crossing can result in either of two fairly stable excited states. (The five processes involved are listed in Fig. 4, together with their typica. rates.) From the groundstate, $S_{0}$, absorption is very fast. Because reaction (5) requires both a change in state and a spin fiip, it almost never occurs, even though it is fast. Intersystem crossing is quite slow, compared with the other processes, but it is the most typical way to populate the $T_{1}$ state, which is the triplet in its lowest vibrational state. The relatively stable higher energy states, then, are $S_{1}$ and $T_{1}$.

In Fig. 5, we show various processes that can depopulate the states $S_{1}$ and $T_{1}$. Only two involve photochemical reaction. Most photochemical oxjdations of organic molecules with oxygen do not produce volatile species. ${ }^{12}$

The $T_{1}$ state could be fairiy reactive, but its population is low in comparison with $S_{1}$, and it is less energetic (Fig. 4 and Table 3 ).

Note that fluorescence occurs only from the excited singlet state and is very fast compared with phosphorescence, which occurs only from the triplet state. (This explains why some materials can be "pumped up" and seen to phosphoresce in a dark room for several seconds or more.) We can see, however, that there are many routes available to depopulate the excited states and that the radiative (phosphorescence and fuorescence) and nonradiative transitions availahle will, in combination, usually be faster than photochemical rates. This-combined with our empirical knowledge that photochemical processes are not very efficient (plants are about $1 \%$ efficient) and wavelength-dependent (we are dealing with a continuous spectrum)-leads us to believe that photolysis, although possible, is not a major contributor to ignition. Most of the deexcitation transitions that occur involve only the release of heat.

To summarize, we have concluded that photochemistry will not be pa.ticularly important, but we still acknowledge that atsorption is wavelengthdependent, even though we must ignore it in what follows because there is no appropriate information available. ${ }^{11}$ We will handle the partitioning of incident energy in another way (described later).

\subsection{Beyond Photochemistry}

Even in the absence of quantitative information sbout specific room fumishing, we can do some simple calculations that are instructive- if nui conclusive. One method of calculating surface temperature will be shown. Jor example, suppose we take a hypothetical, theoretically dense, organic polymer, and stipulate that $99 \%$ of the energy deposited shall be absorbed in the first centimeter of depth. (We allow tite material to be moderately transparent.) We disallow heat-transport processes of any sort, so the temperature distribution will be independent of flux. (Our rationale for this hypothetical case is explained later.)

The material will be pure, homogeneous, and-to make it easy-isotropic. We insist that the absorption of light follow Beer's law, i.e.,

$\log \frac{l(x)}{I_{0}}=-\beta x$

where

$$
\begin{aligned}
\mathbf{I}(\mathrm{x}) & =\text { intensity at depth } \mathrm{x}, \\
\mathrm{l}_{0} & =\text { initial intensity at } \mathrm{x}=0, \\
\beta & =\text { absorptivity at theoretical density. }
\end{aligned}
$$

If we want the intensity to drop by two orders of magnitude by the time $x=1 \mathrm{~cm}$, then we set $\beta=2 \mathrm{~cm}^{-1}$. We set the initial intensity on the 


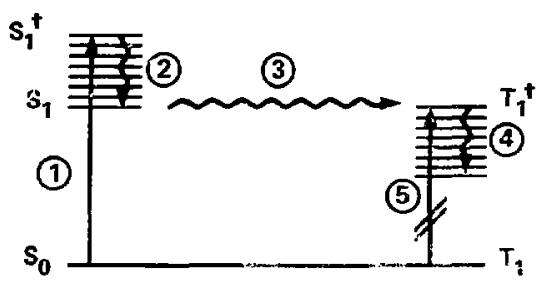

\begin{tabular}{|c|c|c|}
\hline Process* & Nome & Rate (s ') \\
\hline 1. $s_{0}+h v_{1}-s_{1}^{t}$ & Absorption & $10^{15}$ \\
\hline 2. $S_{1}^{\dagger} \rightarrow S_{1}+\Delta$ & Vibrational relax: ${ }^{\prime}: i_{1}$ & $16^{-32}$ \\
\hline 3. $S_{1}-T_{1}^{t}$ & Intersystem crossing & $10^{6}-10^{10}$ \\
\hline 4. $T_{1}^{4}-T_{1}+A$ & Vibrational relaxation & $10^{12}$ \\
\hline 5. $s_{0}+h v_{2}-\tau_{1}$ & Absorption & $10^{15}$ \\
\hline
\end{tabular}

* The symbol $\boldsymbol{A}$ indicates lieat production.

Fig. 4. Excitation processes for formaldehyde. (The horizontal dimension is used only to show the distinction between the singlet and triplet states.)

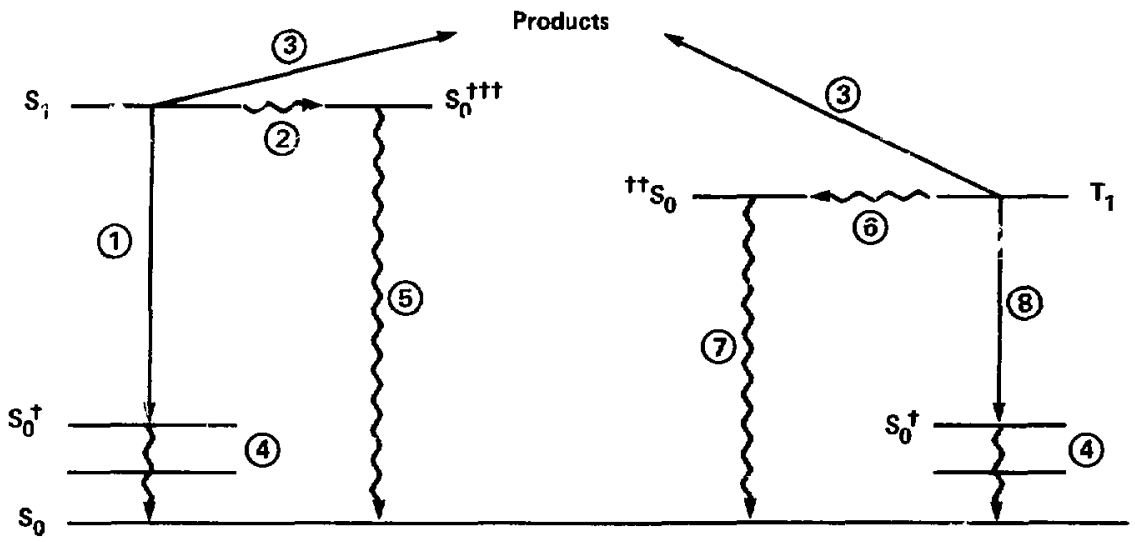

\begin{tabular}{|c|c|c|}
\hline Process" & Name & Rate $\left(s^{-1}\right)$ \\
\hline l. $S_{1}-S_{0}^{t}+h v_{1}$ & Fluorescence & $10^{5}-10^{9}$ \\
\hline 2. $s_{1}-s_{0}^{H+t}+\Delta$ & Internal convernion & $10^{5}-10^{10}$ \\
\hline 3. $S_{1} \rightarrow$ prostucts & Pholorenction & $10^{2}-10^{10}$ \\
\hline 4. $s_{0}^{+}-S_{0}+s$ & Vibrational relaxation & $10^{11}-10^{12}$ \\
\hline 5. $S_{0}^{++t}-S_{0}+A$ & Vibrational relaxation & $10^{11}-10^{12}$ \\
\hline 6. $T_{1}-S_{0}^{4+}+\Delta$ & Internyatem crowing & $10^{-2}=10^{6}$ \\
\hline 7. $s_{0}^{H}-S_{0}+h v_{p}$ & Vibrational relaxation & $10^{12}$ \\
\hline 8. $S_{0} T_{1}-S_{0}^{*}+h v_{p}$ & Phosphorescence & $10^{-2}-10^{3}$ \\
\hline
\end{tabular}

Fig. 5. De-excitation processes for formaldehyde. 
plastic surface at the intensity at $4.6 \mathrm{mi}$ (i.e., $35 \mathrm{cal} / \mathrm{cm}^{2}$ ) reduced by the window-related losses ( $9.6 \%$ reflection and $9.4 \%$ absorption) for a fluence of $28.4 \mathrm{cal} / \mathrm{cm}^{2}$. We can probably argue that dirt on the window or screens or the presence of storm windows would reduce it further. To bring it close to the estimated Encore fluence, we arbitrarily set it at $25 \mathrm{cal} / \mathrm{cm}^{2}$. Then $I(x)=$ $25 \mathrm{cal} / \mathrm{cm}^{2} \exp (-4.606 \mathrm{x})$. To convert the change of energy fluence with depth to a heating effect, we need a value for heat capacity, $C$, and density, $\rho$. Then the drop in intensity of the radiant energy is directly related to an increase in the temperature of the plastic. Furthermore, the temperature gradient can be extrapolated to see what the surface temperature might be and in particular if it has reached or exceeded the autoignition tentperature for that material in air. That is, through a given small thickness, $\Delta \mathrm{T}=\Delta \mathrm{I} / \rho \mathrm{C} \Delta \mathrm{x}$, where $\Delta \mathrm{T}$ is the temperature change. Using values typical if polypropylene $\left(\rho=0.9 \mathrm{~g} / \mathrm{cm}^{3}\right.$ and $C=0.443$ $\left.\mathrm{cal} / \mathrm{g} \cdot{ }^{\circ} \mathrm{C}\right)$ and setting $\Delta \mathrm{x}=0.1 \mathrm{~cm}$ gives the data presented in Table 4 . Linear extrapolation of the temperature gradient to the surface underestimates the surface temperature slightly because the temperature rises more steeply than linearly. The error would be greater if the absorption were stronger.

With a full centimeter thickness of polypropylene absorbing in this manner, this calculation shows the surface rises $310 \mathrm{~K}$ above ambient to about $610 \mathrm{~K}$, which should be well below the autoignition temperatures, even though we ignored the temperature dependency of heat capacity. Regardless, the calculation shows that if the light is absorbed in a moderately transparent material, then the surface temperature does not get high enough for ignition to occur. Some autoignition temperature ranges are given in Fig. 6 for various synthetic and natural polymers. ${ }^{13}$

\subsection{Surface Absorption: Allowance for Thermal Transport}

The previous calculation stipulated that light was absorbed to a substantial depth. Except for certain fabrics that frequently appear to be transparent because of space between fibers, most furniture coverings appear opaque. The way radiar: transfer normally is handled is to stipulate that absorption occurs only on the surface. This is an excellent assumption for electronic conducting materials, but its validity is much poorer when applied to nonconductors. Consequently, in what follows, surface temperatures will be consistently over estimated. The part of the light that is absorbed is described in terms of an absorptivity with a value less than one. This is the counterpart to the emissivity factor that occurs with the Stefan-Boltzman constant in the radiant heattransport equation. Thus, a single constant is used to quantify the absorptise behavior over the entire spectrum in question. Th s has berome an acceptable simplification becaus $\rightarrow$ earlier we concluded that absorption at any wavelength contributes only to heatir: ?. If the absorptivity were urity, the material would be a perfect blackbody absorber, and absorption would occur at any wavelength. If

Table 4. Absorption of $25 \mathrm{cal} / \mathrm{cm}^{2}$ in a $1-\mathrm{cm}$ thickness of polypropylene.

\begin{tabular}{lccc}
$\begin{array}{c}\text { Position } \\
(\mathrm{cm})\end{array}$ & $\begin{array}{c}\text { Flux } \\
\left(\mathrm{cal} / \mathrm{cm}^{2}\right)\end{array}$ & $\begin{array}{c}\text { Temperature rise, } \Delta \mathrm{T} \\
(\mathrm{K})\end{array}$ & $\begin{array}{c}\text { Linearly interpolated } \\
\text { or extrapolated } \\
\text { temperature rise } \\
(\mathrm{K})\end{array}$ \\
\hline 0 & 25.0 & 251 & $31 \mathrm{~J}$ \\
0.1 & 15.8 & 160 & 205 \\
0.2 & 9.95 & 100 & 130 \\
0.3 & 6.28 & 63 & 62 \\
0.4 & 3.96 & 40 & 52 \\
0.5 & 2.50 & & 32 \\
\hline
\end{tabular}


Fig. 6. Some autoignition properties of textile materials in air.

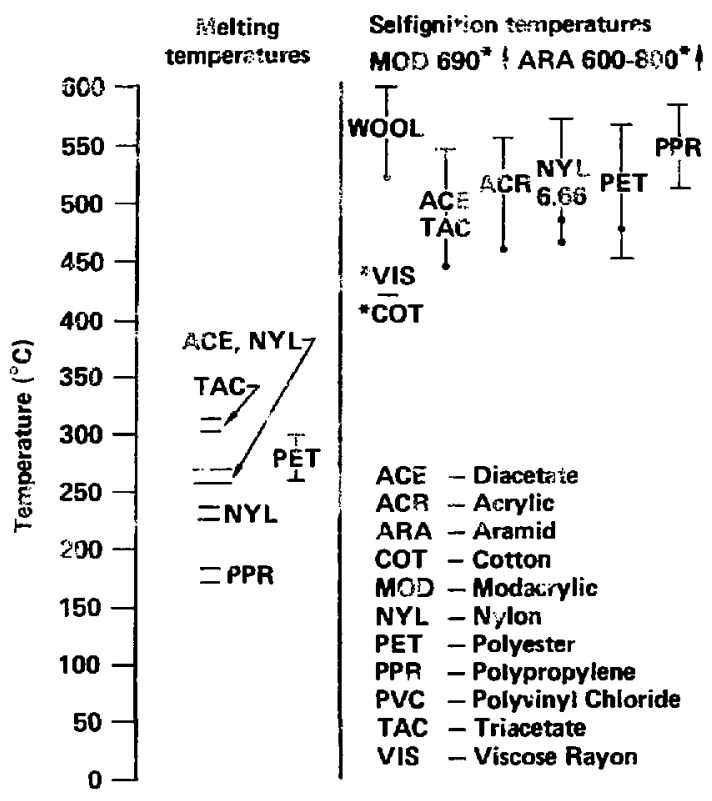

we say $25 \mathrm{cal} / \mathrm{cm}^{2}$ is absorbed and $25 \mathrm{cal} / \mathrm{cm}^{2}$ was incident, then we have a blackbody.

Objer's that absorb heat only on their surfaces logically must have zero transmissivity. The fraction not absorbed is therefore reflected. Also, it is usually true that the interior of an object heats up as the surface temperature rises, since only small changes in temperature are needed for conduction, unless the material is an extremely good thermal insulator. When the surface reaches very high temperatures, additional heat-transport processes come into play. These include reradiation and free convection, which develops from a change in the air density adjacent to the surface. If we try this simple approach-considering only conduction-and stipulate that the physical properties are constant and that no chemical or physical changes occur, then we can use the classical analytical solution reported in Ref. 14. Another restriction is that the flux must be uniform with time. This approach is simply the solution of the transient heat-conduction equation with appropriate restrictions, boundary conditions, and initial conditions, so the problem is tractable. The interested reader is referred to an appropriate text, and only the solution in one dimension is given here. Even more approximate forms allow for linear radiant losses, but they are physically meaningiess and much more complicated. The solution we use is

$$
\begin{aligned}
\Delta \mathrm{T}= & \frac{\mathrm{Ft}}{\rho \mathrm{Cl}}+\frac{\mathrm{F} \ell}{\mathrm{K}} \frac{3 \mathrm{x}^{2}-\ell^{2}}{6 \ell^{2}}- \\
& \frac{2}{\pi^{2}} \sum_{\mathrm{n}=1}^{\infty} \frac{(-1)^{\mathrm{n}}}{\mathrm{n}^{2}} \exp \frac{-\mathrm{dn^{2 } \pi ^ { 2 } t}}{\ell^{2}} \cos \frac{\mathrm{n} \pi \times}{\ell} .
\end{aligned}
$$

where

$$
\begin{aligned}
\Delta \mathrm{T} & =\text { temperature rise, } \\
\mathrm{F} & =\text { incidant flux at } \mathrm{x}=\ell \\
\mathrm{t} & =\text { time, } \\
\rho & =\text { density, } \\
\mathrm{C} & =\text { heat capacity, } \\
\ell & =\text { specimen thickness, } \\
\mathrm{K} & =\text { thermal conductivity, } \\
\mathrm{d} & =\text { thermal diffusivity }=\mathrm{K} / \mathrm{C} \rho
\end{aligned}
$$

Its virtue is that anyone can use it to obtain hand calculated estimates of temperature changes for various combinations of physical preperties. Note 
that the solution corresponds to a first term that reflects a linear increase in temperature with time, and a second term that depends on both time and position due to thermal conduction. If we limit ourselves to the front surface $(x=P)$ and deliver the fluence in a uniform flux of $8.3 \mathrm{cal} / \mathrm{cm}^{2} \cdot \mathrm{s}$ for $3 \mathrm{~s}$, we can calculate the front-surface temperat ire for a variety of materials. We can thus determine approximately if they are likely to ignite or if they will be strong reradiation sources.

The first item of interest is wall material: plaster or gypsum board. (We ignore any paint or wallpaper covering.) When $\mathrm{K}=3 \mathrm{cal} / \mathrm{cm} \cdot \mathrm{s} \cdot \mathrm{deg}$, $\mathrm{t}=3 \mathrm{~s}, C=0.26 \mathrm{cal} / \mathrm{g} \cdot \mathrm{deg}, \rho=2.3 \mathrm{~g} / \mathrm{cm}^{3}$, and $\ell=1 \mathrm{~cm}$, then the temperature rise is calculated to be $42^{\circ} \mathrm{C}$. Over this temperature range, the thermal properties are not likely to change, and the high-temperature heat-removal processes (reradiation and convection) would be un important. We conclude that the light energy from the explosion would make the walls warm, but not hot enough to act as secondary radiators to additionally heat the furnishings. With respect to reradiation, we have erred on the conservative side because the walls would not really act as blackbody absorbers, and would diffusely reflect about half the light that fell on them. (This is to say, for the truncated solar spectrum, the absorptivity is more likely to be around 0.5 than 1.0; see Ref. 15.)

The second material of interest for calculating temperature rise is fabric, which we take to be $0.1 \mathrm{~cm}$ thick. It could serve as either drapery or upholstery covering. We will specify, as in our earlier example, that the staterial is polypropylent. Common experience shows that synthetic polymers, particularly in fabric or sheet form, can he transparent or at least translucent. In a typical roum. however, most fabrics appear to be opaque. Curtains are a notable exreption, but this is due more to open space between the fibers than to transparency of the fiber itself. Indeed, typical fabrics are $90 \%$ voids, ${ }^{\text {, h }}$ so this observation regarding thin fabrics is hardly surprising. Fine weaves are nearly $14 \%$ of their material's theoretical density, whereas coarse weaves are about $9 \%$. (Yarn twist also contributes to fabric density.) Fabrics found in home furnishings cover this range. Now, the polypropylene is in the form of a woven- or knit-fiber fabric, so we use a reduced density level of $10 \%$ of theoretical. The thermal conductivity is somewhere between that of air and that of the solid. In making this approximation, we were optimistic, setting the value for the property equal to that of full-densi ; polypropylene, which is about $3 \times 10^{-4} \mathrm{cal} / \mathrm{cm} \cdot \mathrm{s} \cdot \mathrm{deg}$., which maximizes thermal conductivity. Using the same so' $u^{\prime \prime}$ on (Eq. 5) as before, the temperature rise is calculated to be about $2300^{\circ} \mathrm{C}$. It must be recognized that the fabric will not be a blackbody surface absorber, that the physical properties are not constant, and that all the other approximations and restrictions may cause this calculated temperature rise to be too high. Even so, we conclude from this calculation that heat from thermonuclear fireballs can ignite draperies at some distance, which corresponds with observation. A more accurate calculation appears in the next section for people who might wish to do more realistic calculations with a computer.

The last material we consider using this simple solution is plastic foam. (More discussion on real materials and furnishings appears later.) We chose polyvinyl chloride because we could determine its material properties. We elected to use $10 \%$ of theoretical density, which is at the high end of the range for foams. The thickness is taken to be $1 \mathrm{~cm}$. The full density is $1.4 \mathrm{~g} / \mathrm{cm}^{3}$, the fulldensity heat capacity is $0.4 \mathrm{cai} / \mathrm{g} \cdot{ }^{\circ} \mathrm{C}$, and the fulldensity themal conductivity is $4 \times 10^{4} \mathrm{cul} / \mathrm{cm} \cdot \mathrm{s} \cdot{ }^{\circ} \mathrm{C}$ The temperature rise on the front surface is calculated to be $1828^{\circ} \mathrm{C}$, which implies that ignition could occur.

Now briefly consider the issue of thermal pulse on floor covering. We have selected a burst height of $7500 \mathrm{ft}$ and a dariage level to struct: res that still allows examination of flashover within a room. This occurs when the maximum free-field overpressure is 4 psi (or at $4.6 \mathrm{mi}$ ). In this case, the angle of the light from the center of the fireball is $17.4^{\circ}$ above horizontal as it enters the room. As the fireball expands, rises, and cools, the angle will be greater, but we are concerned more with the highest intensity period. Moreover, suppose we have a $12-\times 12-\mathrm{ft}$ room with a $8-\mathrm{ft}$ ceiling (which is common) and that we fit it with a window that is $4 \mathrm{ft}$ high and $6 \mathrm{ft}$ wide located $3 \mathrm{ft}$ from the floor. Then the light (the spectrum described earlier) from the early fireball passing through the window impinges on the wall opposite the wind : $w$ and/or some of the furnishings. It does not fall directly on the fleor, except for a couple of feet adjacent to the wall opposite the window, where it is at a very low angle that decreases its average fluence. At the 2-psi distance, it would miss any carpeting entirely because of the still lower angle at the greater distance. Other room configurations can be postulated, but our focus remains on other kinds of furnishings. From these purely geometric considerations, carpeting will probably not be the fuel initially ignited, butwhether illuminated or not-it is a source of fuel for subsequent fire development. 


\subsection{Real Furnishings}

Draperies range from very sheer to very heavy, typically lined with less costly fabric, and occasionally lined with thermal trarriers. They may or may not be treated with dyes or fire retardants. ${ }^{17}$ The synthetic fibers used include acetate, acrylic, anidex, modacrylic, nylon, olefin, polyester, and rayon. These are generic terms and the monomers used in some of them can be modified and blended to produce a broad spectrum of fibers and fabrics. Cotton may also be used.

There has been a continual trend away from the natural fibers (cotton and wool) to this array of manmade fibers. Table 5 il? ustrates the point. ${ }^{18}$ There is little reason to believe the trend has reversed.

Upholstered furniture usually uses foams that can include some of the polymers already mentioned, but frequently draw also from other generic families such as vinyls, ether-based urethanes, and synthetic rubbers. They often have inert fillers such as $\mathrm{BaSO}_{4}$ added to make them: stiffer. The most common flame retardants in urethane foams are chlorinated phosphates. A typical construction arrangement for a chair would include the outer fabric, possibly an interior fabric, polyester fiberfill, polyether-based polyurethane foam, and a wooden frame with springs. The sides of the chair would use a lower-density foam and might omit the polyester fill. A recliner chair is simpler, with vinyl (naugahyde) directly covering a foam layer. ${ }^{19}$ The chairs in many offices have a tough fabric over high-density molded foam on a rigid plastic (probably polystyrene) back and seat.

These descriptions show the diversity of materials and combinations of them found in furnishings. This variety, along with other complications, makes confident prediction of fire ignition and growth in a room located in a community under nuclear attack very difficult, if it is to be based only on theoretical considerations. ("Vte" difficult" does not imply impossible, however.) Experiments would not be so difficult, but to do them properly would be quite expensive.

\subsection{Material Properties}

Better analysis of fire ignition and growth requires not only the physical properties used so far, but also thermochemical information. This would inciude enthalpies and entropies for whatever chemical reactions might occur, along with their respective rate constants. Also needed would be similar information regarding changes in physical state (melting and evaporating). Simple stoichiometric calculations show that in a closed room the oxygen is soon exhausted and fire development depends on adequate ventilation, tluid dynamics, and mass transport processes. In this study we restrict ou: attention to the more readily available properties of density, heat capacity, and thermal conductivity.

The density of materials can vary between formulations, but the spread of values and change with temperature is rather modest near room temperature. Values for some typical polymers are given in Table 6 (Ref. 20). Hundreds of other polymers are available, bu: physical property data for them are not available in standard references. These data could be obtained, however, if there was interest in performing calculations to predict their behavior under the conditions being considered.

Heat capacity shows substantial variability, particularly with temperature. Because of this added dimension of substantive change, only two examples are given (see Table 7 and Ref. 21). The changes are quite dramatic, and in general measured values are not available much above room temperature, and certainlu not at temperatures

Table 5. Trends in use of natural synthetic fibers (total U.S. usage $\times 10^{6}$ pounds).

\begin{tabular}{lcccc}
\hline & Year & Wool & Cotton & Synthetic \\
\hline Home furnishings & 1970 & 90 & 1257 & 1683 \\
& 1975 & 32 & 906 & 2294 \\
& 1981 & 29 & 774 & 2737 \\
& & & & \\
Industrial and other & 1970 & 9 & 711 & 1391 \\
consumer uses & 1975 & 6 & 491 & 1997 \\
& 1981 & 12 & 391 & 2914 \\
\hline
\end{tabular}


Table 6. Ranges of specific gravity for some polymers at room temperature.

\begin{tabular}{lc}
\hline \multicolumn{1}{c}{ Material } & Density range $\left(\mathrm{g} / \mathrm{cm}^{3}\right)$ \\
\hline Acrylics & $1.16-1.20$ \\
Phenolics & $1.25-1.34$ \\
Phenol-furfural & $1.3-2.0$ \\
Polyethylene & $0.92-0.93$ \\
Silicones & $1.40-2.04$ \\
Vinyl butyral & $1.05-1.50$ \\
Vinyl chloride & $1.2-1.6$ \\
\hline
\end{tabular}

Table 7. The temperature dependence of heal capacity in polymers.

\begin{tabular}{ccc}
\hline $\begin{array}{c}\text { Temperature } \\
\left({ }^{\circ} \mathrm{C}\right)\end{array}$ & $\begin{array}{c}\text { Polymethylmethacrylat: } \\
\text { (J/K.g) }\end{array}$ & $\begin{array}{c}\text { Polystyrene } \\
\text { (J/K.g) }\end{array}$ \\
\hline 0 & 1.25 & 1.19 \\
50 & 1.50 & 1.26 \\
100 & 1.72 & 1.84 \\
190 & 2.38 & \\
240 & 4.69 & \\
300 & 10.55 & \\
\hline
\end{tabular}

that reach or exceed the autoignition temperatures. The variability below these temperatures still profoundly affects the maximum surface temperature when it is pulse tested. Thermoplastic materials should normally show a substantial endothermic melting enthalpy that could be mistaken for-or calculationally treated as-a large increase in heat capacity sver the melting temperature range. In a fabric or a foam, the heat capacity of the two-phase medium (one is air) is accurately represented by taking the polymer volume fraction and multiplying it by the fulldensity heat capacity. This ignores the heat capacity of air, but that is an acceptable approximaticin for this work.

Thermal conductivity is almost as variable as heat capacity. Figure 7 shows the values for polycarbonate given by four different investigators. ${ }^{22}$ It is immediately apparent that the values obtained in different experiments are quite variable. Also, the thermal conductivity increases by slightly less than a factor of two over the temperature range studied. In the present analysis, a more interesting range would be $300 \mathrm{~K}$ to $1000 \mathrm{~K}$, but such data are not available. Just as the temperature range is not directly applicable, neither is the choice of polymer appropriate as an example of one found in home furnishings. The data shown simply illustrate the problem of obtaining suitable data for calculations. The justification for showing it still holds, however. The thermal conductivity of most polymers found in home furnishings seems to fall within about a factor of two of polyvinyl chloride (PVC) at a given temperature. This is the reason PVC foam was chosen in the calculated example, and two measured values of the thermal conductivity of PVC (Ref. 21) are shown in Fig. 7 for the sake of comparison.

Representation of the thermal conductivity of a foam or fabric is more complicated than representation of heat capacity. The thermal conductivity of air is not negligible, particularly when air can be $95 \%$ or more of the volume of the system. The thermal conductivity of most polymers is only several times as high as air. Also, the thermal conductivity of air increases with temperature proportionally more than that of the polymer. This is illustrated by the fact that for air the thermal conductivity increases from $0.0186 \mathrm{~W} / \mathrm{m} \cdot \mathrm{K}$ at $311 \mathrm{~K}$ to $0.0364 \mathrm{~W} / \mathrm{m} \cdot \mathrm{K}$ at $532 \mathrm{~K}$, and for PVC the corresponding increase is from $0.15 \mathrm{~W} / \mathrm{m} \cdot \mathrm{K}$ to $0.19 \mathrm{~W} / \mathrm{m} \cdot \mathrm{K}$.

The eouation of Meredith and Tobias ${ }^{2.3}$ was chosen to represent the thermal conductivity of foam (where it should be quite accurate) and fabric (where it is not clear how to do it) as well. It is given in Eq. (6):

$$
\begin{aligned}
K_{m}= & \frac{2\left(K_{d}+2\right)+2\left(K_{d}-1\right) f}{2\left(K_{d}+2\right)+\left(K_{d}-1\right) f} \\
& \times \frac{(2-f)\left(K_{d}+2\right)+2\left(K_{d}-1\right) f}{(2-f)\left(K_{d}+2\right)+\left(K_{d}-1\right) f},
\end{aligned}
$$

where

$$
\begin{aligned}
K_{m}= & K_{m} / K_{c}, \\
K_{d}= & K_{d} / K_{c}, \\
K_{d}= & \text { the thermal conductivity of the pure } \\
& \text { dispersed phase, } \\
K_{c}= & \text { the thermal conductivity of the pure } \\
& \text { continuous phase, } \\
K_{m}= & \text { the macroscopic thermal conductivity } \\
& \text { of the } 2 \text {-phase medium, } \\
f= & \text { the volume fraction of the dispersed } \\
& \text { phase. }
\end{aligned}
$$

This expression is theoretically valid for a random dispersion of spheres of wide size distribution in a continuous second phase. The heat flux must be orthogonal to the temperature gradient, and both the flux and temperature must be 
Fig. 7. A comparison of thermal conductivity values for polycarbonate obtained by various investigators compared with the value of polyvinyl chloride.

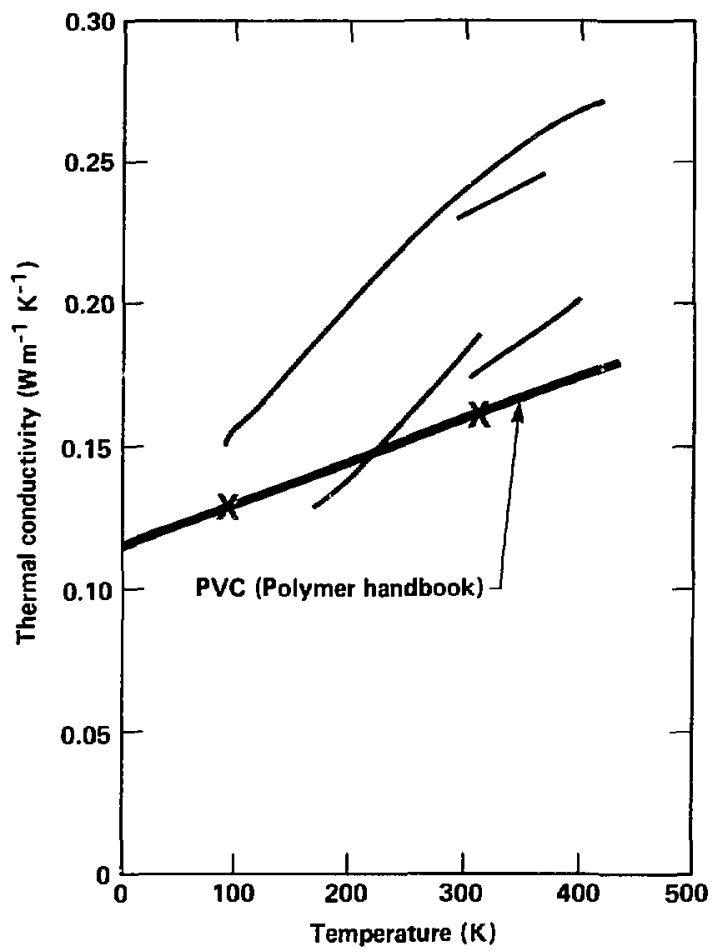

continuous at the interfaces between phases. These conditions are all met as long as we disallow melting and other drastic changes in the material. It should adequately represent a closed-cell foam.

\subsection{Numerical Integration of the Heat-Conduction Equation}

The calculations done were to simulate the early time-temperature response of a piece of modern furniture when exposed to $25 \mathrm{cal} / \mathrm{cm}^{2}$ and $8 \mathrm{cal} / \mathrm{cm}^{2}$ inside a house, as noted earlier in this report. The furniture was simulated as a $1-\mathrm{mm}$ layer of polypropylene fabric covering a thick piece of PVC foam. The fabric was taken to be $90 \%$ voids and the foam $95 \%$ voids. Material properties were handled as previously described, using Equation 6. The shape of the thermal pulse was that shown in Fig. 1, but without the initial sharp spike. Spectral sensitivity for absorptioni and reemission of radiation were averaged by making the gray-body approximation and setting the absorptivity and emissivity both equal to 0.5 at all temperatures. It was stipulated that the furniture reradiated into an environment at $300 \mathrm{~K}$. All absorption and reradiation were stipulated to occur at the front surface of the fabric. Heat losses from the front surface were allowed to develop by both reradiation and the development of natural convection. The correlation given by Wong ${ }^{24}$ based on local Prandtl and Grashof numbers was used for predicting heat loss by natural convection. Of the physical properties we used, the one expected to change the most was the heat capacity. Consequently, we allowed it to increase linearly by a factor of four from 300 to $1000 \mathrm{~K}$ (which 
seems reasonable, in view of the information in Table 7 for other plastics). The calculations were performed using the TACO2D computer model. ${ }^{25}$

The first calculations we did were for no front-surface heat losses, constant properties, and a 3-s steady pulse. After $1 \mathrm{~s}$, we were able to reproduce the simplified analytic solution (results in Section 2.5 ) to much better than $1 \%$. This gave us confidence in the reliability of the numerical model, recognizing that major simplifications in both methods have been required for them to be used at all.

Some of the results are given in Figs. 8 and 9. Temperature is plotted against time for both the outer surface of the fabric and the interface between fabric and foam. In Fig. 8, the autoignition temperature is reached on the outer surface in $0.25 \mathrm{~s}$. In Fig. 9, we went further away from the explosion to $8 \mathrm{cal} / \mathrm{cm}^{2}$ on the furnishings (about the 2-psi distance) and found the autoignition temperature was still exceeded. It has been argued that for cellulose, at least, reaching the auioignition temperature on the outer surface is adequate to assure a fire start, ${ }^{2 n}$ but not everyone agrees. $^{27}$

Using a temperature-dependent thermal conductivity would drop the front-surface temperature. Including endothermic chemical reactions below the ignition temperature would keep it cooler, although some investigators believe this to be a minor effect. ${ }^{28}$ Again, it must be emphasized that setting both emissivity and absorptivity at $\mathbf{9 . 5}$ is arbitrary on our part. It has been proven wrong for some other materials, ${ }^{29}$ but we have no appropriate data to do it differently. Finally, we must remember that at early times, pyrolysis might produce smoke that could partially shield the surface from part of the remainder of the thermal pulse, and we have ignored this, again because data are lacking. (This phenomenon has been observed experimentally, however. ${ }^{30}$ ) it is simply one more complicating fact that may be added to those already mentioned. More elaborate calculations with more and better data could address all these questions

\subsection{Fire Development Beyond Ignition}

Small-scale tests of the rate at which the fire spreads cannot, in general, be extrapolated to large scale to predict the progression of fire development. ${ }^{31}$ Simply developing reliable small-scale tests to predict fire spread rate after ignition has been a significant long-term activity at the $\mathrm{Na}$ tional Bureau of Standards and elsewhere. ${ }^{32.33}$ It is uften said that the single most important parameter of a fuel is its maximum heat-release rate. Ti-3le 8 shows some data on mattresses ${ }^{34}$ that suggest very strongly that synthetic polymers can

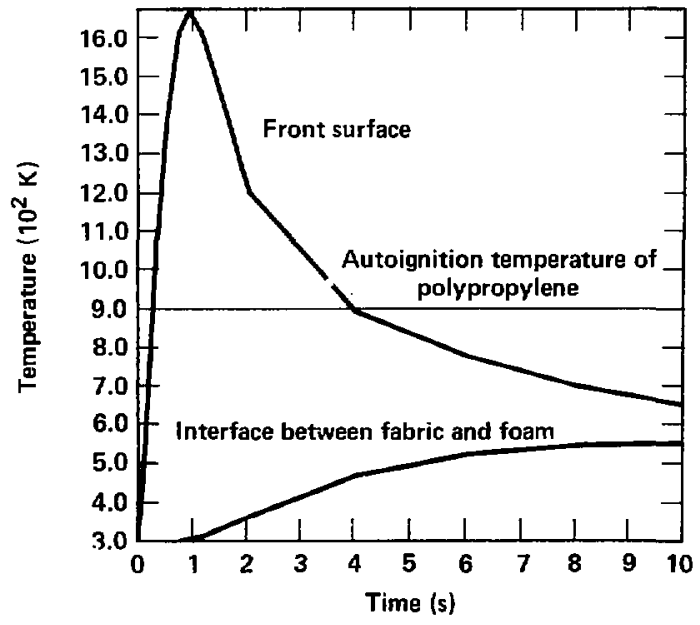

Fig. 8. Temperature histories for two locations in a piece of simulated furniture with $25 \mathrm{cal} / \mathrm{cm}^{2}$ incident on the front surface of the fabric. 
Fig, 9. Temperature histories for two locations in a piece of simulated furniture with $8 \mathrm{cal} / \mathrm{cm}^{2}$ incident on the front surface of the fabric.

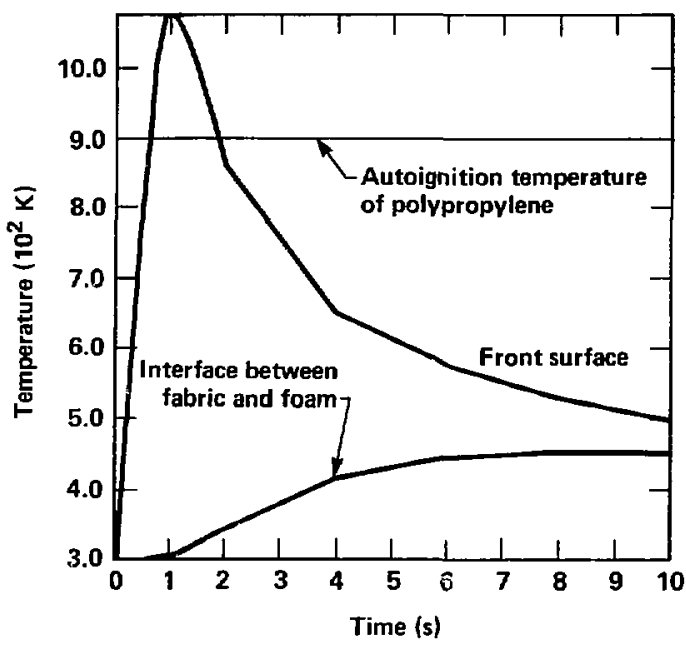

Table 8. Mattress specimens tested in full and in bench-scale.

\begin{tabular}{|c|c|c|c|c|c|}
\hline Specimen & $\begin{array}{c}\text { Combustible } \\
\text { mass } \\
\text { (kg) }\end{array}$ & $\begin{array}{l}\text { Total } \\
\text { fuel } \\
\text { (M) }\end{array}$ & $\begin{array}{l}\text { Filling } \\
\text { material }\end{array}$ & $\begin{array}{l}\text { Ticking } \\
\text { material }\end{array}$ & $\begin{array}{c}\text { Bench-scale } \\
\text { neat release rate } \\
\left(\mathbf{k W} / \mathbf{m}^{2}\right)\end{array}$ \\
\hline 1 & If & 415 & Polyurethane & Polyvinyl chloride & 399 \\
\hline 2 & $t$ & $J 84$ & Polyurethane & Polypropylene & 1,38 \\
\hline 3 & 11 & 225 & Cotton felt & Polyvinyl chloride & 60 \\
\hline 4 & 19 & 742 & Latex & Polyvinyl chloride & 479 \\
\hline 5 & 6 & 175 & Polyurethane & Rayon & 179 \\
\hline 6 & 12 & 268 & $\begin{array}{l}\text { Cotion/nylon/ } \\
\text { polyester } \\
\text { batting }\end{array}$ & Polyester & 127 \\
\hline 7 & 13 & 287 & Cotton, jute & Cotton & 43 \\
\hline 8 & 18 & 474 & Neoprene & Cotton & R9 \\
\hline 9 & 3.2 & 95 & Polyurethane & Palyvinyl chloride & 152 \\
\hline 10 & 6 & 149 & Neoprene & Polyvinyl chloride & 83 \\
\hline
\end{tabular}

equal or exceed the heat-release rate of cotton. (Recall that cotton and other cellulosic materials were used in the Encore Event.) As noted earlier, prediction of fire development is complicated by room geometry, the amount and arrangement of fuel, where the fire started, and the availability of ventilation, in addition to the kind(s) of fuel. There is little reason to believe these factors would be unimportant for the situation considered here. Research continues; it is not yet developed to the point where it could be applied to nuclear war. ${ }^{33-38}$ Current theory does not include non-uniform pulse heating in different parts of the room, for example.
During the fire development, much of the rapidly heated fuel (but not all of it) will be quickly ignited simultaneously, and some of that which is not ignited will have had its surface rapidly preheated to a temperature below that required for autoignition. This would apply to some of those surfaces that received the thermal pulse at angles less than $90^{\circ}$. Thus, progression to fully developed fire could occur more rapidly than is usually observed. On the other hand, if the light entering the room fell on a bare plaster wall (see Section 2.5) there is little reason to believe anythisig would ignite. 


\subsection{Interaction of Ignited Fires with the Blast Wave}

The most plausible explanation put forth so far for the extinguishment of flames by blast is that of flame displacement followed immediately by cooling of the main fuel. Flame displacement requires that the particle velocity in the wind behind the shock front exceed the flame speed, a condition that is easily met. More important is dilution of the flaming vapors to a concentration below their flammability limit as they are displaced. Flame displacement and extinguishment shuts off the thermal feedback to the main fuel from which the flammable vapors are produced pyrolytically. The fuel must be cooled sufficiently so it does not reignite.
Room geometry and location of fuel influence blast interaction with fire, which further complicates the physical siruation and makes accurate prediction of behavior more difficult. This line of reasoning has been roughly substantiated experimeritally but the most recent attempts to quantify it failed. ${ }^{36,37}$

For the highest flux used in this report the shock front arrives at $17 \mathrm{~s}$ after detonation, which may be ample time for a well established fire to develop. It is less likely that well established fires could be extinquished by the blast behind a shock front, as was observed in the Encore Event.

In 1983, FEMA sponsored an experiment during the Direct Course Event that was to simulate the rapid fire development at Encore and see if such fires could be extinguished by blast. ${ }^{39}$

\section{Conclusion and Recommendation}

Based on the informatiun we have (which can be described only as sketchy;, we conclude that it is !ike! $y$ that, with rapid heating as described, ronms furnished with modern synthetic materials will be ignited and will produce well-f:stablished fires in short periods of time (a few minutes or less). Our conclusion leads to a recommcndation and a suggestion for further consideration.

- Recommendation: conduct an extended series of full-scale tests on rooms appropriately furnished and exposed to a range of fluxes and fluences of the solar spectrum, to resolve the many outstanding questions raised.

- Suggestion: as a civil-defense measure, in the event of "crisis relocation" (a situation in wrich people would have at least several days' notice to evacuate), advise residents to cover their windows with foil or craw the draperies and move all the other flammable material well away from them before evacuating. (The draperies could act as sacrificial heat absorbers, and they might prevent the rest of the room from igniting.) Flaming draperies might act as firebrands, but the time to flashover conditions, if they occur, should then be closer to normal. By reducing the incidence of flashover, these measures might make wnat fires occur more manageable. 


\section{References}

1. H. D. Bruce, Incendiary Effects on Buildings and Interior Kindling Fuels, Forest Products Laboratory, USDA, Madison, WI, Report UKP-64 (1953).

2. K. P. Laughlin, "Thermal Ignition and Response of Mate-ials," Operation Teapot-1955, Office of Civil and Defense Mobilization, Report WT-1198 (December 1957), Issuance Date: July 20, 1960.

3. S. Glasstone and P. Dolan, Eds., The Effects of Nuclear Weapons, 3rd ed., USDOD and USERDA (1977), p. 287.

4. The Effects of Nuclear War, Office of Technology Assessment, U.S. Congress (1979), p. 122.

5. S. Glasstone and P. Dolan, Eds., The Effects of Nuclear Weapons, 3rd ed., USDOD and USERDA (1977), p. 41 .

6. Ibid., p. 117

7. P. Klein, "Measured Absorption Coefficients," in Proc. SPIE 204, 77 (1979).

8. R. C. Weast, Ed., Handbook of Chemistry and Physics, 64th ed., CRC. Press, Boca Raton, FL (1983), p. E363.

9. D. Wolf-Dieter et al., "Low Emissivity and Solar Control Coatings on Architectural Glass," Proc. SPIE 37, 324 (1982).

10. R. C. Weast, Ed., Handbook of Chemistry and Physics, 64th ed., CRC Press, Boca Rat:-n, FL (1983), p. F200.

11. G. Mandicos, Amer. Assn. Textile Chemists and Colorists, personal communication (November 1983).

12. N. J. Turro, Photochemistry of Organic Molecules, American Chemical Society, Washington, D.C. (1974).

13. J. F. Krasney, Flami Retardant Polymeric Materials, vol. 3, M. Lewin, et al., Eds. (Plenum, New York, NY, 1982), p. 190.

14. H. Carslaw and J. Jaeger, Conduction of Heat in Solids, 2nd ed. (Oxford-Clarendon Press, New York, NY, 1977), p. 112.

15. F. Kreith, Principles of Heat Transfer (Internat. Text Book Co., Scranton, PA, 1960), p. 191.

16. J. Sharman, Consumer Products Jafety Commission, personal communication (November 1983).

17. M. Lewin, S. M. Atleas, and E. M. Pearce, Eds., Flante Retardant Polymeric Materials, vol. 3 (Plenum, New York, NY, 1982).

18. Man-Made Fiber Fact Book Update (Man-Made Fiber Producers Assn., Washington, D.C., 1982).

19. H. Stone, General Foam Corp., personal communication (November 1983).

20. T. C. DuMond, Ed., Engineering Materials Manual (Reinhold Publishing Co., New York, NY, 1951), p. 172.

21. J. Brandrup and E. H. Immergut, Eds., Polymer Handbook, 2nd ed. (Wiley-Interscience, New York, NY, 1975).

22. NBS Monograph 132, A Compilation and Evaluation of Mechanical, Thermal, and Electronic Properties of Selected Polymers.

23. E. Meredith and C. Tobias, "Conduction in Heterogeneous Systems," in Advances in Electrochemistry and Electrochemical Engineering, vol. 2, P. Delahay, Ed. (Interscience Publishers, New York, NY 1962), p. 30 .

24. H. Y. Wong, Heat Transfer for Engineers (Longman, London, 1977), p. 51.

25. P. J. Burns, TACO2D-A Finite Element Heat Transfer Code, Lawrence Livermore National Laboratory, Livermore, CA, UCID-17980-Rev. 2 (1982).

26. N. J. Alvares and S. B. Martin, "Mechanisms of Ignition of Thermally Irradiated Cellulose," in 13th litt. Symposium on Combustion (1970), p. 905.

27. T. Kashiwagi, "A Radiative Ignition Model of a Solid Fuel," Combustion Science and Technology 8, 225 (1974).

28. C. C. Ndubizu and P. Durbetaki, Fire Research 1, 281 (1973).

29. J. R. Welker, H. R. Wesson, and C. M. Sliepcevich, Fire Teclinology 5, 59 (1969).

30. S. Glasstone and P. Dolan, op. cit., p. 284.

31. J. deRis, "Flammability Testing: State of the Art," Proceedings 17th Conference on Fire and Blast Effects of Nuclear Weapons, Lawrence Livermore National Laboratory, Livermore, CA, CONF-8305107 Uune 1983). 
32. C. Adams and S. Davis, Development of the Flooring Radiant Panel Test as a Standard Test Method, National Bureau of Standards Report No. NBSIR 79-1954 (March 1980).

33. V. Babrauskas, "Fire Engineering Test Development: Bench Scale Tests to Predict Full Scale Behavior," National Bureau of Standards for Presentation at 7th UJNR Panel on I ire Research and Fire Safety (October 1983), p. 4.

34. Ibid., Table 1.

35. L. Pietrzak and J. Ball, A Physically Based Fire Supression Computer Simulation. Mission Research Corporation, Report No. MRC-R-732 (April 1983).

36. J. Backovsky, S. Martin, and R. McKee, "Experimental Extinguishment of Fires by Blast," SRI International, Report No. PYU-3341 (May 1982).

37. A. M. Kanury, Respose Mechanism: BlastıFire lnteraç̧ion. Federal Emergency Management Agency work unit $2564 \mathrm{H}$ (November 1983).

38. . H. Thomas ef al., "Flashover and Inctabiltties in Fire Behavior," Combustion and Flame 38,159 (1980).

39. R. C. McKee, Ir., and S. B. Martin, Los Alamos Scientific Laboratory, Los Alamos, NM, private communication (1984). 


\section{Distribution List}

Dr. David W. Bensen

Emergency Preparedness Rc search Divi.ion Natioral Preparedness Programs Fede, il Emergency Management Agency Washıngton, D.C. 20472

Mr. Don Bettge Industrial Protection Division National Preparedness Programs Federal Emergency Management Agency Washington, D.C. 20472

Defense Technical Information Center Cameron Station

Alexandria, VA 22314

Assistant Director

Energy \& Vatura Resources

Office of Science ar. rechnology Policy

Executive Dffice Building

Washington, D.C. 20500

Mr. Carl Wiehle

Defense Inteiligence Agency

Attn: CKW DB-4C2

Washington. D.C. 20301

Director, Defense Nuclear Agency

Attn: Michael Frankel

Washington, D.C. 20305

Command and Control Technical Center

Department of Defense

The Pentagon

Washington, D.C. 20301

Mr. Samuel Kramer

National Bureau of Standards

Room B-124, Bldg 225

Washington, D.C. 20234

Mr. William Parker

National Bureau of Standards

Building 224 - Room A-345

Washington, D.C. 20234

Dr. John Rockett

National Bureau of Standards

Center for Fire Research

Building 224 - Room B-260

Washington, D.C. 20234
Director

Department of Military Application

Department of Energy

Washington, D.C. 20545

Los Alamos Scientific

Laboratory

Attn: Document Library

Los Alamos, NM 87544

R. G. Hickman

Lawrence Livermore National Laboratory

University of California

Box 808, L-140

Livermore, CA 94550

Oak Ridge National Laboratory

Attn: Librarian

P.O. Box $X$

Oak Ridge, TN $\mathbf{3 7 8 3 0}$

Emergency Technology Division

Oak Ridge National Laboratory

Attn: Librarian

Oak Ridge, TN 37830

Chief of Engineers

Department of the Army

Attn: DAEN-RDZ-A

Washington, D.C. 20314

Director, Army Materials and Mechanics Research Center

Attn: Technical Library

Watertown, MA 02172

Assistant Secretary of the Army (RD\&A)

Attn: Deputy ASA for (RD\&S)

Washington, D.C. 20310

U.S. Army Training and Doctrine Command

Fort Monroe

Hampton, VA 23651

Director, U.S. Army Ballistic Research

Laberatory

Atto: Document Librory

Aber deen Proving Ground, MD 21005 
Mr. William Taylor

Ballistic Research Laboratory

Aberdeen Proving Ground, MD 21005

Direcior, U.S. Army Engineer Waterways Experiment Station

Attn: Document Library

P.O. Box 631

Vicksburg, MS 39180

Mr. W. L. Huff

USAE Waterways Experiment Station

P.O. Box 631

Vicksiurg, MS 39180

U.S. Army Combined Arms Combat Development Activity

Fort Leavenworth, KA 66027

Civil Engineering Center AF/PRECET

Attn: Technical Library

Wright-Patterson Air Force Base

Dayton, $\mathrm{OH} \$ 5433$

Air Force Weapons Laboratory

Attn: SUL Technic al Library

Kirtland Air Force Base

Albuquerque, NM 87117

Dr. Conrad Chester

Oak Ridge National Laboratory

P.O. Box X

Oak Ridge, TN 37830

Dr. Clarence R. Mehl

Division 7112

Sandia National Laboratories

Box 5800

Albuquerque, NM 87185

National Council on Radiation

Protection and Measurements

7910 Woodmont Avenue

Bethesda, MD 20014

Mr. Phil Nash

Southwest Research Institute

6220 Culebra Road

San Antonio, TX 78284

Dr. Wilfred E. Baker Wilfred Baker Engineering

218 E. Edgevood Place

San Antonio, TX 78209
Mr. C. Wilton

Scientific Service, Inc.

517 East Bayshore

Redwood City, CA 94063

Dr. William Christian

Underwriters' Laboratories, Inc.

333 Pfingsten Road

Northbrook, IL 60062

Dr. Donald Drzewiecki

Calspan Corporation

P.O. Box 400

Buffulo, N] 14225

Mr. Clay P. Butler/Mr. Dick Foster

SRI International

333 Ravenswood

Menlo Park, CA 94025

Air Force Weapons Laboratory

Civil Engineering Division

Kiritand Air Force Base

Albuquerque, NM 87117

Hudson Institute

Quaker Ridge Road

Croton-on-Hudson, NY 10520

Mr. Fred Sauer

Phyics International Company

2700 Merced Street

San Leandro, CA 94577

The Dikewood Corporation

1613 University Blvd, N.E.

Albuquerque, NM 87102

Dr. Anatole Longinow

IITRI

10 West 35th Street

Chicago, IL 60616

Mr. Leo A. Schmidt

Institute for Defense Analyses

Program Analysis Division

1801 N. Beauregard Street

Alexandria, VA 22311

The RAND Corporation

Attn: Document Library

1700 Main Street

Santa Monica, CA 90401 
Director

Lovelace Foundation

5100 Gibson Blvd, S.E.

Albuquerque, NM 87108

Dr. Donald Sachs

Kaman Sciences Corp.

1911 Jefferson Davis Highway

Arlington, VA 22202

Center for Planning and Research

2483 E. Bayshore, Suite 104

Palo Alto, CA 94303

Dr. Fred Offensend

SRI International

333 Ravenswood

Menlo Park, CA 94025

Mrs. Ruth Schnider

Center for Planning and Research

2473 E. Bayshore

Palo Alto, CA 94303

Mr. Walter Strope

Center for Planning and Research

5600 Columbia Pike-Suite $10 \mathrm{I}$

Bailey's Crossroads, VA 22041

Dr. Dennis Holliday

R\&D Associates

P.O. Bo: 9695

Marina del Rey, CA 90291

Attn: Mr. Ed L. Hill

Research Triangle Institute

P.O. Box 12194

Research Triangle Park

North Carolina 22709

Mr. Robert Fristrom

Johns Hopkins Applied Physics

Laboratory

Johns Hopkins Road

Laurel, MD 20707

Dr. John Cockayne

Senior Scientist

Science Applications, Inc.

1710 Goodridge Drive

P.O. Box 1303

McLean, VA 22101

Mr. Marvin Drake

Science Applications, Inc.

1200 Prospect Street

La Jolla, CA 92037
Mr. Richard Laurino

Center for Planning and Research

2483 E. Bayshore

Palo Alto, CA 94303

Mr. John Rempel

Center for Planning and Research

2483 E. Bayshore

Palo Alto, CA 94303

Professor R. K. Pefley

University of Santa Clara

Santa Clara, CA 95053

Dr. Ing. P. G. Seeger

Forschungsstelle fuer

Brandschuetztechnik

Unjversity of Karlsruhe (TH)

75 Karlsruhe 21

Postfach 63380

West Germany

Secretaire d'Administration

Ministere de l'Interieur

Direction Generale de la

Protection Civile

rue de Louvain, 1

100 ) Brussels, Belgium

Canadian Defence Research Staff

Attn: Dr. K. N. Ackles

2450 Massachusetts Ave, N.W.

Washington, D.C. 20008

H. L. Murphy Associates

Box 1727

San Mateo, CA 94401

Mr. Harvey G. Ryland

Ryland Research, Inc.

5266 Hollister Avenue

Suite 324

Santa Barbara, CA 93111

Technology \& Management

Consultants

330 Washington Street

Suite 613

Marina del Rey, CA 90291

Jefe, Seccion de Estudios y Planification

c/Evaristo San Miguel, 8

Madrid-8

Spain 


\section{Ministero dell Interno \\ Direzione Generale della Protezione Civile 00100 Rome, Italy}

Directeur de la Protection Civile

Ministere de l'lnterieur

36 Rue J. B. Esch

Grande-Duche de Luxembourg

Directeur Organisatie

Bescherming Bevoling

Ministry of Interior

Schedeldoekshaven 200

Postbus 20011

2500 The Hague, Netherlands

The Head of Sivilforsvaret

Sandakerveien 12

Postboks 8136

Oslo dep

Oslo 1, Norway

Dr. Don Scheuch

430 Golden Oak Drive

Portola Valley, CA 94025

Director Civilforsvarsstyrelsen

Stockholmsgade 27

2100 Copenhagen 0

Denmark

Direction de la Securite Civile

Ministere de l'Interieur

18 Rue Ernest Cognac

92 Levallois (Paris) France

Bundesministerium des Innern

Graurheindorfer Strasse 198

5300 Bonn 1

West Germany
Ministry of Social Service

11 Spartis Street

Athens, Greece

Almannavamir Rikisins

Reykavik, Iceland

Stato Maggiore Difesa Civile

Centro Studi Difesa Civile

Rome, Italy

Civil Emergency Planning Directorate

North Atlantic Treaty Organization

1110 NATO, Belgium

Servico National de Proteccao

Civil

Rua Bela Vista a Lapa, 57

1200 Lisbon, Portugal

Civil Defense Administration

Ministry of Interior

Ankara, Turkey

Home Office

Scientific Advisory Branch

Horseferry House

Dean Ryle Street

London SW1P2AW

England

Dr. Jakob Gut

Forschungsinstitut fuer militaerischs Bautechnik (FmB)

Zurich 1 auf der Mauer 2

Switzerland

Bengt Vretblad, Dr. Eng-

Research Manager

Royal Fortifications Administration

FACK

5-631 89 Eskilstuna

Sweden 